\title{
A CONTRIBUIÇÃO DE PAULO FREIRE À EDUCAÇÃO NA ÁFRICA: UMA PROPOSTA DE DESCOLONIZAÇÃO DA ESCOLA
}

\author{
PERI MESquidA* \\ JULIANO PEROZA* \\ ABDELJALIL AKKARI ${ }^{* * *}$
}

\begin{abstract}
RESUMO: Este artigo apresenta uma leitura crítica da participação de Paulo Freire no processo de descolonização na África durante a década de 1970, bem como uma análise da atualidade de sua proposta político-pedagógica para a realidade educacional daquele Continente. No primeiro momento, procuramos situar social, histórica e culturalmente a colonização na África, suas características e as particularidades da dominação. No segundo momento, apontamos as principais propostas político-educacionais de Paulo Freire para a África pós-colonial, deparando-se com a pluralidade cultural africana. E, para finalizar, apresentamos um panorama conjuntural da situação político-educacional africana, de modo a identificar a atualidade da contribuição de Freire diante dos novos desafios educacionais naquele Continente.
\end{abstract}

Palavras-chave: Paulo Freire. África. Educação. Descolonização.

\section{Paulo Freire's contribution to education in Africa: A PROPOSAL FOR SCHOOL'S DECOLONIZATION}

ABSTRACT: This article presents a critical reading of Paulo Freire's participation in the process of decolonization in Africa during the 1970s, as well as an analysis of today's relevance of his political-pedagogical proposal for the education's reality in that continent. Firstly, it tries to situate the social, historical and cultural aspects of colonization in Africa, its characteristics and particularities of domination. Subsequently, we consider Freire's main political-educational proposals for the post-colonial Africa encountering the African cultural plurality. Lastly, we present a comprehensive overview of

\footnotetext{
* Programa de Pós-Graduação em Educação da Pontifícia Universidade Católica do Paraná (PUC-PR). Curitiba (PR) - Brasil.

** Instituto Federal de Educação, Ciência e Tecnologia do Paraná (IFPR). Irati (PR) - Brasil.

*** Faculdade de Psicologia e de Ciências da Educação da Universidade de Genebra. Genebra - Suíça. Contato com os autores: <mesquida.peri@gmail.com>
} 
the political-educational situation in Africa in order to identify the contemporaneity of Freire's contribution against the backdrop of the new educational challenges in the African Continent.

Key words: Paulo Freire. Africa. Education. Decolonization.

\section{L'apport de Paulo Freire à l'éducation en Afrique: UNE PROPOSITION DE DÉCOLONISATION DE L'ÉCOLE}

RÉSUMÉ: Cet article présente une lecture critique de la participation de Paulo Freire dans la procédure de décolonisation en Afrique pendant les années 1970, ainsi qu'une analyse de l'actualité de sa proposition politico-pédagogique pour la réalité scolaire de ce Continent. Tout d'abord, nous cherchons à placer la colonisation en Afrique sous un regard social, historique et culturel, aussi bien ses caractéristiques et particularités de la domination. Ensuite, nous indiquons les plus importantes propositions politiques éducatives de Paulo Freire pour l'Afrique post-colonial, où se trouve une vaste pluralité culturelle. Et, pour finir, nous présentons un panorama conjoncturel de la situation politique et éducative africaine, afin d'identifier l'actualité de la contribution de Freire devant les nouveaux défis scolaires dans ce Continent.

Mots-clés: Paulo Freire. Afrique. Éducation. Décolonisation.

\section{Introdução}

A

o considerar a importância do engajamento político-educacional de Paulo Freire nos países africanos no período pós-colonial, raras vezes se apresenta uma visão conjuntural dos desafios de reconstrução nacional, os quais se iniciam em pleno processo revolucionário de lutas pela independência do jugo colonial e do "aprendizado da autonomia" por parte dos colonizados. Esse contexto passa a ser o terreno fértil para que Freire coloque à prova os pressupostos teóricos e práticos de sua pedagogia político-libertadora, na própria "eclosão" dos fatos que abrem as possibilidades para que vários povos possam escrever sua própria história.

Ao mesmo tempo em que essa experiência gerou muitas expectativas no que se refere às possibilidades de seu "método" (de alfabetização) de potencializar e contribuir para a consolidação do êxito revolucionário, a prática revelou que a complexidade conjuntural do contexto social, econômico e cultural foi decisiva para que se impusessem alguns impasses. Por isso é que se faz de extrema importância investigar os fatos para além das conclusões sobre o eventual "fracasso" do seu método na África, a fim de que sejam problematizados os múltiplos fatores que contribuíram para que isso acontecesse e, portanto, superar uma visão simplista de que as "experiências" podem ser transplantadas inteiramente sem que sejam consideradas as características e os limites do contexto do(s) país(es) receptor(es). 
Por isso, tentaremos refazer este percurso para propormos uma leitura atualizada da obra de Freire para a África. A permanência dos mecanismos de dominação pós-colonial ainda revela a vigência da opressão coordenada pelas elites africanas e multinacionais do mundo inteiro que veem na África uma oportunidade para realização de interesses comerciais. No entanto, expressões emergentes de formas de educação comunitárias, as quais brotam das realidades locais, podem ser contextos fecundos de interlocução com as propostas freirianas.

\section{Paulo Freire diante dos desafios educacionais à época do contexto colonial e pós-colonial africano}

Inúmeras discussões já foram realizadas para analisar a pertinência ou relevância do método de alfabetização de jovens e adultos de Paulo Freire na África (OLIVEIRA; PIRES; VENTORIM, 2000; FAUNDEZ, 1989; FREIRE e al, 1982; DAVIDSON, 1978; entre outros). As polêmicas em torno deste "período" de experiência educacional na vida do educador brasileiro provocam ainda hoje os pesquisadores do seu pensamento a problematizar cada vez mais o contexto em que se deu esta prática, para que sejam superadas conclusões minimalistas a respeito da validade e universalidade de sua proposta político-pedagógica. Assim, para contribuirmos com o debate, procuraremos no início deste artigo contextualizar historicamente sua presença de pedagogo-político frente aos desafios da descolonização.

Primeiramente, é preciso compreender que o "encontro" de Paulo Freire com a África acontece simultaneamente no contexto em que se dão vários movimentos de independência em países daquele continente. Faundez (2010) sugere que é preciso diferenciar a especificidade deste processo de "descolonização" de acordo com as características históricas da dominação africana em contraste com o continente latino-americano, berço e ponto de partida em que se forjaram as origens do pensamento freiriano. Segundo o autor,

[...] podemos dizer que nos anos 60-70, o continente africano vive a luta pela primeira independência (essencialmente política), embora esta tenha elementos que caracterizam também a chamada segunda independência (notadamente econômica). Independência então ao mesmo tempo política e econômica, mas acrescentemos um elemento completamente novo: o elemento cultural, que diferencia ostensivamente o processo histórico da África e da América Latina. (FAUNDEZ, op. cit., p. 4)

O processo de descolonização no continente africano é algo recente, se comparado com a América Latina. Enquanto nesta o colonialismo que perdurou por mais de três séculos implicou uma aparente homogeneidade cultural (principalmente no que se refere à predominância das línguas portuguesa e espanhola nos territórios 
nacionais), na África, este processo de "unificação cultural" com o predomínio da língua do colonizador não foi o mesmo. Apesar de o início da colonização portuguesa no continente africano datar desde o século XV, é somente no século XIX que se intensifica e se planifica a dominação colonial, quando, a partir do momento em que se consolida a Revolução Industrial na Europa, as potências europeias se encontram para realizar a Conferência de Berlim, ${ }^{1}$ em 1884-1885, a fim de dividir o exercício da soberania sobre o continente africano, fato sem precedentes na história: "jamais um grupo de Estados de um continente proclamou, com tal arrogância, o direito de negociar a ocupação e a partilha de outro continente" (BOAHEN, 2010, p. 35).

Neste sentido, é preciso considerar relevante o apontamento feito por Faundez em referência ao "elemento cultural" como fator de diferenciação quando se compara a independência do jugo colonial entre os dois continentes. Praticamente, a independência da maioria dos países africanos se dá numa relação direta, quase que de "primeira mão" com os seus colonizadores, num período de tempo relativamente curto para a consolidação da hegemonia cultural dos colonizadores e sua incorporação (por exemplo, a língua) por parte dos colonizados. É preciso considerar também que a colonização na África passa primeiro pela dominação política, comercial e militar em detrimento da colonização populacional (com exceção da Argélia e África do Sul), enquanto na América Latina há um aumento do contingente demográfico de origem europeia (brancos) entre os séculos XIX e XX.

Portanto, para compreender a especificidade da relação de dominação neste contexto, é indispensável que façamos referência a Memmi (2004) e Fanon (2011), autores que melhor desenvolveram uma análise sobre essa temática. Ambos exerceram influência considerável sobre o pensamento de Freire, antes mesmo que este sequer imaginasse que estaria diretamente envolvido com a reflexão sobre os rumos a serem tomados no processo de libertação de alguns países africanos. Isso nos ajudará a esclarecer melhor as possibilidades e as limitações históricas que se impuseram como desafios da atuação político-pedagógica de Paulo Freire no continente que despertou seu interesse de educador militante.

Fanon (2011) vê a relação do colonizador e do colonizado a partir da força de atração que o primeiro exerce sobre o segundo. O colonizador reconhece em si mesmo a figura desbravadora da história, sente-se construtor da realidade e interventor nesta, considerando sua "vida uma epopeia, uma odisseia. Ele é o começo absoluto: 'esta terra, fomos nós que a fizemos'. Ele é a causa contínua: 'se partirmos, tudo estará perdido, esta terra voltará à idade média"' (FANON, op. cit., p. 363). Portanto, o mundo do colonizador não é o mundo do colonizado. Diante deste mundo é que a consciência do colonizado se vê encoberta, envolta, de modo que, ao mesmo tempo em que o "mundo do colonizador pode ser um mundo hostil, que rejeita", é também um mundo impelido pela "inveja" de substituí-lo. Assim, continua Fanon (op. 
cit., p. 464): "Este mundo hostil, pesado, agressivo, por que rejeita com todas as suas asperezas a massa colonizada, representa não o inferno do qual se desejaria afastar-se o mais rapidamente possível, mas um paraíso ao alcance da mão, protegido por terríveis cães de guarda".

Fanon mostra muito bem como se constituem, respectivamente, os dois mundos: o do colonizado e o do colonizador. Na relação de poder que se estabelece entre os dois há uma disputa que implica sempre o desejo de dominação, de reprodução da situação colonial, e não sua erradicação. O colonizado tem como única referência o mundo do colonizador e, portanto, aspira chegar ao seu lugar: sonha os seus sonhos, deseja os seus desejos e vive em função da superação da situação de "inferno" gerada pelo dominador, para chegar ao "paraíso", que é o lugar onde se encontra o colonizador. Para Fanon, o olhar do colonizado reflete o olhar do próprio colonizador.

Já Memmi (1967), ao analisar a dinâmica da dominação colonial na Argélia (datada no ano de 1831), faz uma leitura da colonização e como esta se efetiva e se legitima sem que haja resistência e tentativa de subversão por parte do colonizado, o que ele denomina de mistificação ideológica da classe dirigente:

\begin{abstract}
Verifica-se, certamente - em determinado ponto de sua evolução -, certa adesão do colonizado à colonização. Mas essa adesão é resultado da colonização e não sua causa: nasce depois e não antes da ocupação colonial. Para que o colonizador seja inteiramente senhor, não basta que o seja objetivamente, é preciso ainda que acredite na sua legitimidade; e para que essa legitimidade seja completa, não basta que o colonizado seja objetivamente escravo, é necessário que se aceite como tal. Em suma, o colonizador deve ser reconhecido pelo colonizado. (MEMMI, op. cit., p. 84)
\end{abstract}

O complexo de dependência que o colonizado sente num primeiro momento perante o colonizador é o reconhecimento da superioridade deste. Desafiar o colonizador é colocar em risco a própria existência, uma atitude que demonstra passividade do colonizado, pois arriscar-se, num primeiro momento, é interpretado como possibilidade de morte e não de vida. Para Memmi, a legitimidade da opressão se sustenta pelo próprio "retrato" que o colonizado, com sentimento de inferioridade, tem do colonizador: uma imagem imponente, audaciosa, que não tem medo de arriscar-se em impor sua cultura como verdadeira, portanto, que acredita na sua proeminência.

Estas análises sobre a ambiguidade presente na condição existencial do colonizado feitas por Albert Memmi e Frantz Fanon, ao descreverem as razões íntimas que perpetuaram o jugo da colonização na África, influenciam decisivamente no sentido do conceito de "prescrição" utilizado por Paulo Freire:

Por isto, o comportamento dos oprimidos é um comportamento prescrito. Faz-se à base de pautas estranhas a eles - as pautas dos opressores. Os oprimidos, que introjetam a "sombra" dos opressores e seguem suas pautas, temem a liberdade, na medida em que 
esta, implicando a expulsão desta sombra, exigiria deles que "preenchessem" o "vazio" deixado pela expulsão do outro "conteúdo" - o de sua autonomia. (FREIRE, 1987, p. 18)

O não reconhecimento da situação de opressão faz com que o oprimido se identifique com o opressor, assumindo em sua experiência existencial uma postura de aderência a este e reproduzindo em sua própria vida os aspectos que são inerentes à realidade opressora. Expulsar a sombra da dominação e assumir sua própria autonomia exige do dominado a capacidade de situar-se historicamente, no que diz respeito às possibilidades que tem para construir-se a si mesmo, sem a intervenção de outro que prescreva seus atos. O que precisa fazer é descobrir-se capaz, expulsar de si o medo e, ao mesmo tempo, o fascínio que sente pelo opressor. Porém, preencher o vazio desta expulsão exige que se assuma um novo modo de vida a ser constituída numa nova relação intersubjetiva, de maneira que seja superada completamente a antiga. Assim, o processo de independência seria, para Freire, um momento "pedagógico" propício para o "nascimento" e educação do "novo" povo africano.

Desse modo, Freire utiliza-se da leitura que estes intelectuais fizeram do colonialismo na África, bem como de suas próprias conclusões explicitadas em sua Pedagogia do Oprimido, para compreender a interiorização da realidade colonial que se propagou na América Latina por mais de quatro séculos (mesmo após a independência) e no continente africano, de modo que se mantivessem as estruturas que permitem as relações de dominação entre os indivíduos. Nesse sentido, Freire vai mais longe do que Memmi e Fanon, de modo a perceber que a reprodução da opressão por parte de quem a sofre não faz parte somente da condição de colonização, mas se trata de uma realidade estrutural socioeconomicamente injusta. A prescrição nada mais é do que a condição em que o oprimido (em qualquer situação de opressão) se encontra quando não consegue agir com autonomia, segundo seus próprios critérios, falar suas próprias palavras. Como não consegue "ser", caminhar com os próprios pés, precisa dos ditames de alguém que o controle, que diga o que tem que fazer. Para Freire (1987, p. 18), "o conhecimento que têm de si mesmos, como oprimidos, se encontra, contudo, prejudicado pela 'imersão' em que se acham na realidade opressora". Esta imersão não possibilita o reconhecimento da contradição entre eles e o opressor, pelo contrário, mantém uma identificação com o dominador.

Essa percepção sobre a complexidade que delineia a perpetuação da reprodução das relações de poder será central para compreendermos a especificidade histórico-cultural e os desafios socioeconômicos que se impuseram ao "êxito" das propostas político-pedagógicas de Freire na África, na década de 1970. A consolidação do processo de independência em países de pequeno contingente demográfico; depredados economicamente pela ocupação colonial; com uma multiplicidade de línguas tribais "orais" (sem tradição escrita), portanto, com mais de $90 \%$ de analfabetos; a pluralidade étnica, todos esses são fatores que não podem ser ignorados. 
A rigor, também é preciso situar Freire dentro do movimento de independência nos países africanos de colonização portuguesa, ainda em relação ao advento na Europa de um pensamento "terceiro mundista" e anticolonialista influenciado pelas ideias de libertação e independência que circulavam e que foram muito propagadas nas décadas de 1960 e 1970. Essas ideias foram absorvidas por determinados organismos internacionais, como a ONU, por meio da Unesco, pela Igreja Católica, por meio do Concílio Vaticano II - que era expressamente contrário à opressão colonial - e o Concílio Mundial de Igrejas, cujo secretário executivo era o teólogo protestante Philip A. Portter (de 1972 a 1984), personalidade de destaque na defesa da liberdade e dos direitos humanos, além de ser negro e de origem africana, apesar de ser originário de Roseau, capital de Dominica. Assim, havia um quadro favorável no que se refere ao respaldo institucional dado a intelectuais, no caso de Paulo Freire e sua equipe do Instituto de Ação Cultural (Idac), para pensar estratégias de superação do colonialismo.

Consideraremos também que se vivia na época em que se intensificava a Guerra Fria, e a África colonizada passava a ser terreno fecundo para a teoria revolucionária marxista, a qual é interpretada mais na perspectiva da luta contra a dominação colonial (étnica) do que na superação dos mecanismos estruturais do sistema capitalista.

Todos estes são fatores indispensáveis para situarmos o quadro conjuntural de opressão com o qual Freire se deparou naquele momento para repensar sua Pedagogia do Oprimido.

\section{As propostas político-educacionais de Freire na África pós-colonial}

A presença de Freire no continente africano acontece por intermédio do Conselho Mundial de Igrejas (CMI), especificamente em alguns países de colonização portuguesa: Guiné-Bissau, Cabo Verde, São Tomé e Príncipe e Moçambique. Mas é prioritariamente em Guiné Bissau que se elabora uma reflexão contextualizada e engajada no que se refere a pensar o papel da educação numa perspectiva libertadora naquele país (FREIRE, 1978). Em primeiro lugar, é preciso levar em conta que Freire se disponibiliza a assessorar o Ministério da Educação sob a responsabilidade de Mário Cabral como militante, e não somente técnico ou burocrata. Em segundo lugar, Freire deixa claro que experiências não se transplantam, mas se reinventam:

\footnotetext{
Na verdade, as experiências não se transplantam, se reinventam. Porque, disto convencidos, uma de nossas preocupações básicas, permanentes, durante todo o tempo em que nos preparávamos, em equipe, para a primeira visita à Guiné-Bissau, foi a de nos vigiar quanto à tentação de, superestimando este ou aquele aspecto desta ou daquela experiência de que antes participáramos, pretender emprestar-lhes validade universal". (Freire, op. cit., p. 12)
} 
Em terceiro lugar, a posição humilde e democrática de aprender com a realidade em que se encontra e, mesmo posicionando-se criticamente contrário às decisões tomadas pelas lideranças que dirigiam o processo de reconstrução nacional, as aceitou respeitosamente.

Um fator a ser considerado é o destaque que Freire dá à categoria “infraestrutura" (base material dos modos de produção) nos escritos, cartas e conversas em que ele fala sobre a educação na África. Insiste em vários momentos que a educação no processo de independência deve estar vinculada ao trabalho manual, bem como sobre a necessidade de criar as condições concretas para que a superação das marcas do colonialismo fossem uma "reafricanização da África".

A principal fonte teórico/prática que serviu de base para a leitura do processo de independência em Guiné-Bissau e São Tomé e Príncipe foi o pensamento do líder revolucionário Amilcar Cabral. Deste, Freire apropria-se de duas ideias principais: a de que a luta pela independência é um "fato cultural e um fator de cultura" (idem, ibid., p. 89), de modo que a prática revolucionária propiciaria as condições concretas para superação da ideologia colonial; e a ideia de "suicídio de classe", em que a classe média iria aderir ao processo revolucionário pela independência para superar o colonialismo. A rigor, pode-se dizer que Freire não acreditava na conversão da classe media como classe, isto é, da burguesia, antes de ter contato com o pensamento de Amilcar Cabral e com a realidade africana. Por isso, "ao comentar a expressão suicídio de classe", cunhada por Cabral, Freire diz que o "que se coloca hoje é o da reinvenção do poder" (GADOTTI; FREIRE, 1996, p. 168). Contudo, antes de sua experiência africana, em um texto escrito em Genebra, em 1970 (O papel educativo das igrejas na América Latina) e reproduzido na obra Ação cultural para a liberdade, em 1982 (FREIRE, 1984), o autor, discutindo o papel das igrejas na educação na América Latina, divide os agentes educativos das igrejas, mulheres e homens, em "espertos" e "ingênuos". Diz ele que, de um lado, se encontram "os ingênuos de diversos matizes, 'inocentes', com a melhor das intenções, na sua percepção da Igreja e da história. De outro lado, os/as que, 'espertamente', escondem sua opção" (FREIRE, 1984, p. 105). Ele escreve, ainda: “Uns e outros 'atravessam' a ideologia das classes dominantes e por ela são 'atravessados', mas os 'espertos' assumem esta ideologia. São bastante conscientes do que fazem" (ibid., p. 106). Mais adiante, observa Freire (1984, p. 106):

Os "inocentes", através de sua própria prática histórica, ao desvelar a realidade e sendo nela desvelados, tanto podem assumir a ideologia da dominação, transformando, assim, sua "inocência" em "esperteza", quanto podem renunciar a suas ilusões idealistas. Neste caso, então, retiram sua adesão acrítica às classes dominantes e, comprometendo-se com as classes oprimidas, iniciam uma nova aprendizagem com elas.

Trata-se de uma aprendizagem que, para Freire, os leva a passar para uma nova condição, isto é, a fazer a sua "Páscoa". Pois, então, "que 'morram' como 
elitistas para renascerem como revolucionários, por mais humilde que seja sua tarefa como tais". Isso porque "Páscoa é morrer para viver" (idem, ibid., p. 107). No livro Cartas a Guiné-Bissau: registro de uma experiência em processo (1978), Freire comenta o significado do papel da burguesia "convertida" no processo revolucionário do continente africano. Diz ele:

Referindo-se ao papel da pequena burguesia no quadro geral da luta de libertação nacional, afirmou Amílcar Cabral: "Para não trair estes objetivos (os da libertação nacional) a pequena burguesia não tem mais que um caminho: reforçar sua consciência revolucionária, repudiar as tentativas de aburguesamento e as solicitações naturais de sua mentalidade de classe, identificar-se com as classes trabalhadoras, não se opor ao desenvolvimento normal do processo da revolução.

Isto significa que, para cumprir perfeitamente o papel que lhe cabe na luta de libertação nacional, a pequena burguesia revolucionária deve ser capaz de se suicidar como classe para ressuscitar como trabalhadora revolucionária, inteiramente identificada com as aspirações mais profundas do povo a que pertence.

Esta alternativa, prossegue Cabral, - trair a Revolução ou se suicidar como classe - constitui a opção da pequena burguesia no quadro geral da luta de libertação nacional". Esta alternativa continua de pé, em todos os campos de atividade, hoje, na luta pela reconstrução nacional, que é o prolongamento daquela. (FREIRE, 1987, p. 20-21)

Na obra Ação cultural para a liberdade, Paulo Freire evoca tanto o sentido vetero-testamentário de Páscoa como "passagem" da opressão da liberdade, quanto aquele encontrado no Novo Testamento, referindo-se à morte e ressurreição de Jesus Cristo. Estaria Paulo Freire nesses comentários, mesmo antes de conhecer o pensamento de Amilcar Cabral, apresentando uma ideia bíblica de suicídio de classe?

Parece que pela primeira vez em sua vida Freire se deparou com as condições históricas concretas em que uma sociedade estava se reinventando numa perspectiva socialista. Assim Freire (1987, p. 91) se refere ao citar Cabral em suas cartas:

\footnotetext{
Uma reconversão dos espíritos - das mentalidades - se revela indispensável à sua (dos intelectuais) verdadeira integração ao movimento de libertação. Uma tal reconversão - reafricanização no nosso caso -, diz ele, pode se operar antes da luta, mas não se completa a não ser no curso daquela, no contato quotidiano com as massas populares e na comunhão de sacrifícios que a luta exige. Sem esta "reconversão", sobre que Amílcar Cabral sempre insistiu, não era possível ao intelectual pequeno-burguês, ontem, encarnar a luta de libertação e nela "reencarnar-se".
}

Por isso, em suas cartas militantes deixa transparecer algumas preocupações centrais quanto às táticas e estratégias que deveriam ser adotadas neste momento de transição: a) como a subsistência está no nível das necessidades gerais da população, o novo sistema educacional não poderia separar trabalho intelectual do trabalho manual, ou seja, teoria e prática deveriam orientar a formação dos novos intelectuais; b) o cuidado que os dirigentes revolucionários deveriam ter, caso não houvesse 
a adesão comprometida dos intelectuais pequeno-burgueses (suicídio de classe) no processo de alfabetização:

[...] na hipótese de não poder contar: I - com camponeses que pudessem ser rapidamente capacitados, como no caso chileno, para o trabalho de alfabetização; II - com jovens urbanos capazes de cometer o "suicídio de classe", preferia dedicar algum tempo à capacitação mais demorada de camponeses para que se tornassem educadores autênticos de seus camaradas. (FREIRE, 1978, p. 92-93)

Freire (op. cit.) percebe que é preferível partir das "bases" para a formação dos novos intelectuais, mesmo considerando que na época $90 \%$ da população de Guiné Bissau era camponesa; c) insistiu no fato de que era preciso situar o planejamento da educação no plano global da reorganização política do Estado, de modo que houvesse organicidade, ou melhor, "metas solidárias" entre as várias "frentes de atuação":

Refiro-me, sim, a um certo número de metas, solidárias entre elas e coerentes com um certo objetivo no campo da organização econômica e social; no da distribuição interna como no do comércio externo; no das comunicações e transportes; no da cultura; no da saúde; no da educação em geral, que a esse objetivo deve servir. (Idem, ibid., p. 112)

Assim, pode-se dizer que a principal preocupação de Freire neste momento da independência foi solidificar as bases para uma autêntica superação da condição colonial. Suas propostas deixam transparecer a visão de um conselheiro estrategista, alguém que se põe numa atitude de diálogo crítico com os dirigentes do novo Estado, que precisa situar-se na história e, ao mesmo tempo, resgatar sua identidade.

No entanto, uma das principais questões que desafiaram Freire a reinventar-se com coerência como político-pedagogo foi a multiplicidade linguística da população, bem como sua característica predominantemente oral. Diante disso, Freire comenta numa carta escrita em julho de 1977 (FREIRE; FAUNDEZ, 1985, p. 67-70), que pode ser resumida nas teses centrais: 1) a leitura da realidade precede a leitura da escrita; portanto, deve-se aprofundar o nível de politicidade da população; 2) a "escrita", num local de tradição oral, precisa ser uma necessidade que nasce das mudanças infraestruturais; assim, a língua é uma questão central que exige profunda reflexão; 3) a alfabetização não pode se dar na língua portuguesa, pois esta está ausente da prática social do povo; 4) é preciso implementar, com a ajuda de linguistas militantes, a sistematização escrita do creoulo e, enquanto isso, priorizar alfabetização em português nas áreas centrais em que este é mais usual; 5) intensificar o trabalho de ação cultural junto à população em geral.

Este último item é enfatizado por Romão e Gadotti (2012, p. 100), ao reproduzirem um trecho do livro de Amilcar Cabral, A arma da teoria (1974): "Sejam quais 
forem as características ideológicas ou idealistas das suas manifestações... é um elemento essencial da história de um povo... O domínio imperialista tem como necessidade vital praticar a opressão cultural, a libertação nacional é, necessariamente, um ato de cultura".

Os autores ainda acrescentam em forma de comentário: “daí a necessidade constantemente reafirmada por ele, do movimento de libertação basear sua ação no conhecimento profundo da cultura de um povo" (idem, ibid.).

Também é importante diferenciar a ação de Freire na Guiné-Bissau daquela levada a efeito em São Tomé e Príncipe, por exemplo. Enquanto na Guiné-Bissau de Amilcar Cabral um significativo número de pessoas não falava o português, mas se diluía em mais de trinta línguas diferentes, o mesmo não ocorria em São Tomé e Príncipe. Vale destacar que o processo de alfabetização desenvolvido por Freire e sua equipe na Guiné-Bissau se defrontou com o problema da língua a ser utilizada. Amilcar Cabral defendia a manutenção e a difusão do português como língua nacional. No entanto, o creoulo era falado por $45 \%$ da população (CABRAL, 1974). Paulo Freire, num livro em pareceria com Antonio Faundez (FREIRE; FAUNDEZ, 1985, p. 126) transcreve uma declaração de Cabral sobre o uso da língua oral e escrita: "A língua não é prova de mais nada, senão um instrumento para os homens se relacionarem uns com os outros". E Freire comenta: "Amilcar Cabral deixava de perceber lamentavelmente a natureza ideológica da linguagem, que não é algo neutro, como lhe pareceu no texto citado. Esta é uma das raras afirmações da obra de Cabral que jamais pude aceitar".

No livro Pedagogia da tolerância (2004, p. 110), Paulo Freire diz ter ouvido da viúva de Amilcar Cabral a seguinte explicação para a defesa do uso da língua portuguesa feita pelo marido:

Na época em que Cabral fez essa afirmação cabia essa análise, e estava havendo um risco, na luta, de uma certa sectarização, que colocava os caboverdianos e os guineenses a serem contra qualquer português, contra a cultura portuguesa, contra a linguagem portuguesa, contra tudo que fosse português. E Cabral achava isso um risco de engrossamento dessa perspectiva que, pare ele, e eu concordo, enfraqueceria a própria luta.

Freire e sua equipe, apesar da consciência que o educador brasileiro tinha do fato que a cultura desempenha papel fundamental na formação da nacionalidade de um povo que passou por um processo de quinhentos de anos de colonialismo - e a língua "oficial" como parte da cultura expressa justamente a visão de mundo do colonizador -, mantiveram a língua portuguesa como se a mesma fosse a língua nacional dos guineenses. Em uma carta de 10 de junho de 1985, enviada a Paulo Freire por Mario Cabral, ministro do Comércio, Pescas e Artesanato da Guiné-Bissau, ao explicar as razões do "fracasso" da campanha de alfabetização no seu país, Cabral 
colocou a escolha da língua portuguesa como o fator fundamental do insucesso da campanha levada a efeito por Freire e sua equipe na Guiné-Bissau.

Freire, em um livro em parceria com Sergio Guimarães (FREIRE; GUIMARÃES, 2003), reconhece que o uso da língua portuguesa na alfabetização dos guineenses, em especial na zona rural, foi um fator para o fracasso do processo de alfabetização na Guiné-Bissau. Finalmente, desafiado por Antonio Faundez a refletir sobre o problema, Paulo Freire desabafa:

[...] no momento em que uma sociedade pede à língua do colonizador que assuma o papel de mediadora da formação do seu povo tem de estar advertida de que, ao fazê-lo, estará, querendo ou não, aprofundando a diferença entre as classes sociais em lugar de resolvê-la. (FREIRE; FAUNDEZ, 1985, p. 127)

A rigor, o povo não estaria dizendo a "sua" palavra, mas a palavra do colonizador. Mesmo assim, a língua do colonizador foi a escolhida para a alfabetização e a educação dos guineenses em lugar do creoulo, língua capaz de unir a nação e lhe dar condições de dizer a "sua" palavra, lendo e escrevendo, escrevendo e lendo, denunciando a opressão e anunciando a libertação; mais ainda, vivendo a "sua" cultura e fazendo dela a expressão da sua nacionalidade.

Diante deste quadro conjuntural, percebemos a complexidade para se avançar politicamente rumo a um projeto de nação autônoma. Suas propostas, apesar de coerentes com sua perspectiva de "inédito viável", não se efetivaram na prática, pois suas opiniões e conselhos estratégicos tinham apenas uma função "consultiva" frente aos que coordenaram o processo de independência, e não "deliberativa". As disputas de interesse no Estado "livre" do jugo colonial se fizeram presentes na voz do presidente Luiz Cabral, quando este se dirigiu a Freire e disse: "teremos de lutar bastante contra as opiniões opostas que você afirma, entre nós mesmos" (FREIRE; FAUNDEZ, 1985, p. 70).

Logo após a independência, percebe-se que não houve propriamente um "suicídio de classe", como diagnosticaram Freire e Cabral, mas um breve "adormecimento" da classe dirigente, que viria a "despertar" como novos colonizadores dentro de seu próprio território. Isto é, na medida em que a independência é conquistada, aqueles que assumem o poder correm o risco de se tornar "novos colonizadores", no sentido de virem a ser opressores do seu próprio povo.

\section{Pertinência da pedagogia de Paulo Freire para a atualidade da edu- cação na África}

Nas duas primeiras partes deste artigo, ao mesmo tempo em que discutimos a experiência de Paulo Freire com a África, demonstramos igualmente o contexto 
colonial e pós-colonial no qual ela se implantou. Na terceira parte do artigo nós analisaremos a relevância atual da contribuição freiriana para a educação na África. Como Freire afirmou em vários de seus escritos, sua pedagogia deve ser objeto de crítica e de transformação permanente, pois não deve ser compreendida como um sistema imutável, ou seja, Freire precisa ser revisitado à luz dos atuais desafios educacionais da África, os quais ainda interpelam uma via emancipatória.

O terreno africano tem uma particularidade quando se trata de colocar em prática as ideias de Paulo Freire sobre uma "pedagogia dos oprimidos". Segundo Cogneau (2006), a África, ao mesmo tempo em que pode ser considerada o continente mais pobre do mundo, é também aquele em que as desigualdades de renda são as mais elevadas. Um Africano de classe média consome duas vezes menos do que um asiático, quatro vezes menos do que um latino-americano, oito vezes menos do que um europeu e 16 vezes menos do que um norte-americano. Da mesma forma, muitos países africanos têm suas capitais caracterizadas por um dualismo escolar ilustrado pela coexistência de onerosas instituições educacionais públicas e privadas e de um setor de educação de base (escolas primárias) com o quadro de pessoal mal preparado, em situações precárias e desigualmente distribuído em todo o território. Neste contexto, a escola desempenha um papel dual, pois ela foi (e é sempre) uma das chaves de acesso não somente aos empregos nos setores modernizados, mas também um meio para se inserir no aparelho do Estado, no qual se encontra o poder político e social. A desigualdade, no que diz respeito ao acesso à escola, implica, por consequência, uma reprodução mais acentuada das elites políticas africanas e, portanto, a perpetuação das desigualdades sociais.

Um estudo recente da Unesco-UIS (2010) demonstra a precariedade da situação educativa na África atual. Enquanto os países do continente buscam atingir a meta do ensino primário universal, a organização internacional estima que cerca de 71 milhões de jovens no mundo estão excluídos do primeiro ciclo do ensino secundário: $40 \%$ estariam na Ásia do Sul e 30\% na África Subsaariana. Nesta última zona, somente 23\% dos jovens em idade de estar no ensino secundário o estão efetivamente; 39\% têm o nível de escolarização primária e 38\% jamais passaram pelos bancos escolares.

A fim de avaliar as perspectivas do desenvolvimento e do pensamento freiriano na África, nos parece importante, de início, abordar a problemática colonial e pós-colonial. Se a abordagem da educação africana em termos de opressores e de oprimidos é ainda pertinente, é preciso compreender que a identidade dos opressores e dos oprimidos mudou desde a independência até o momento presente. Nos anos de 1950 e 1960, o colonizador era branco e europeu, o qual sempre se aproveitou do modo como a África esteve inserida no contexto mundial da globalização neoliberal. Em outras palavras, as multinacionais europeias se aproveitaram ao máximo do cacau da Costa do Marfim ou do diamante congolês. De qualquer forma, contrariamente à época da 
emergência do pensamento de Paulo Freire, o colonialismo interno é um elemento importante na explicação das desigualdades educativas atuais. As elites africanas tomaram o lugar dos ex-colonizadores ao ocupar posição privilegiada no cenário politico e social nacional. A dualidade escolar da época colonial entre as escolas para os colonos e as raras escolas para os nativos africanos foi substituída pela dualidade em diversos níveis: público/privado; rural/urbano; capital/interior do país, entre outros. Não é por acaso que, como afirmamos anteriormente, Freire insistiu em utilizar o termo cunhado por Amilcar Cabral, "suicídio de classe", para analisar o fato de as classes sociais privilegiadas da África trabalharem contra seus próprios interesses, a fim de transformar radicalmente a escola. Contudo, sabemos que lutar contra o colonialismo interno está no limite mais difícil do colonialismo tradicional. Isso exige em particular a ação de movimentos sociais ativos.

Portanto, nos parece indispensável considerar a transformação do Estado em relação à escola pública. Durante a experiência de Freire na África lusófona, o ainda jovem Estado Africano pós-colonial tinha como crédito o fato de ter conquistado a libertação da opressão colonial. Contudo, depois de 40 a 50 anos de independência, o Estado se transformou em predador. Quanto a isso, tomamos como exemplo a escola pública: durante os anos que se seguiram à independência, a África tinha "fome" de escola. As escolas públicas se multiplicaram consideravelmente nas cidades e zonas rurais. O Estado-educador tinha a adesão da população para enviar suas crianças à escola. Havia tamanho entusiasmo em torno da escola que muitos dos líderes da África independente não hesitaram em manter a língua do colonizador como forma de generalizar a escolarização.

Atualmente, o desencantamento escolar está presente em toda parte pela África. A esperança de mobilidade social se transformou em desconfiança em relação ao Estado e à escola. Além disso, o Estado africano, enfraquecido pelas medidas de ajuste estrutural (impostas pelo FMI e Banco Mundial) e sua dependência no que diz respeito à cooperação internacional, assume cada vez menos a sua responsabilidade com a escola pública, pois sequer tem dinheiro para contratar o número necessário de professores. Em muitos contextos, a escola pública depende do financiamento dos pais e das comunidades locais para sobreviver. Em suma, a proposta educativa que Freire introduziu no Estado nacional africano pós-colonial se desintegrou; aliás, começou a se desintegrar logo depois que Freire e sua equipe deixaram o Continente. A indefinição geral de fronteiras entre público e privado torna difícil a operacionalização das proposições freirianas no que se refere à conscientização das massas.

Por outro lado, o desenvolvimento de formas comunitárias de escolarização oferece possibilidades interessantes para a implementação das abordagens inspiradas em Paulo Freire na África, pois, quando a educação é gestada pelas comunidades locais, ela se torna sensível ao contexto local e permite aos seus habitantes a 
possibilidade de escolha das orientações compatíveis com suas referências culturais e suas preocupações socioeconômicas. Nesse sentido, numerosas comunidades estão pressionando pela utilização da língua materna dos alunos, sem excluir o uso das línguas nacionais da época da colonização. Este é um sinal de que os oprimidos começam a colocar em dúvida a ideologia do opressor no nível da superioridade do francês, do inglês e do português, os quais se apresentam como "estandartes" no status de garantia no processo de modernização. No entanto, ao mesmo tempo, em toda a África, o poder econômico e simbólico ainda está conectado ao controle das línguas coloniais.

Não há dúvida de que a contribuição de Paulo Freire representaria, hoje, uma alternativa interessante para reformar a forma escolar pós-colonial africana, pois esta não permitiu que a África avançasse. Todavia, é preciso considerar as importantes mudanças sociais que ocorreram, as quais demandam uma abordagem freiriana, mas adequada à nova situação em que se encontram os países da antiga África portuguesa.

\section{Nota}

1. Disponível em: <http://www.casadehistoria.com.br/sites/default/files/conf_berlim.pdf >. Acesso em: 10 abr. 2012.

\section{Referências}

BOAHEN, A.A. Partilha europeia e conquista da África: apanhado geral. In: BOAHEN, A.A. (Ed.). História geral da África. 2. ed. Brasília, DF: Unesco, 2010. v. 7, p. 43-68.

CABRAL, A. PAIGC: unidade e luta. Lisboa: Nova Aurora, 1974.

COGNEAU, D. L'Afrique des inégalités: où conduit l'histoire? Paris: Rue d'ULM, 2006.

DAVIDSON, B. A liberdade da Guiné: aspectos de uma revolução africana. Lisboa: Sá Corrêa, 1978.

FANON, F. Oeuvres: peau noire, masques blancs; L'an V de la révolution algérienne; Les damnés de la terre; Pour la révolution africaine. Paris: La Découverte, 2011.

FANON, F. Oeuvres: Peau noire, masques blancs; L'an V de la révolution algérienne; Les damnés de la terre; Pour la révolution africaine. Paris: La Découverte, 2011.

FAUDEZ, A. Oralidade e escrita. Rio de Janeiro: Paz \& Terra, 1989.

FAUNDEZ, A. Paulo Freire e sua influência na América Latina e África. In: ENCONTRO INTERNACINAL FÓRUM PAULO FREIRE, 7., Praia, set. 2010. Disponível em: 
$<$ http://www.ipf.org.cv/forum2010/index.php?option=com_content\&view=article\&i $\mathrm{d}=73$ : comunicacao-de-conferencistas\&catid=36:anuncios\&Itemid=81>. Acesso em: 30 mar. 2012.

FREIRE, P. Educação como prática da liberdade. Rio de Janeiro: Paz \& Terra, 1974.

FREIRE, P. Ação cultural para a liberdade e outros escritos. Rio de Janeiro: Paz \& Terra, 1984.

FREIRE, P. Cartas a Guiné Bissau: registros de uma experiência em processo. 2. ed. Rio de Janeiro: Paz \& Terra, 1987.

FREIRE, P. Pedagogia do oprimido. 17. ed. Rio de Janeiro: Paz \& Terra, 1978.

FREIRE, P. Pedagogia da tolerância. São Paulo: Unesp, 2004.

FREIRE, P.; FAUNDEZ, A. Por uma pedagogia da pergunta. 3. ed. Rio de Janeiro: Paz \& Terra, 1985.

FREIRE, P.; GUIMARÃES, S. A África ensinando a gente: Angola, Guiné-Bissau, São Tomé e Príncipe. São Paulo: Paz \& Terra, 2003.

FREIRE, P. et al. Vivendo e aprendendo: experiências do Idac em educação popular. São Paulo: Brasiliense, 1982.

GADOTTI, M. Paulo Freire: uma biobibliografia. São Paulo: Cortez, 1996.

MEMMI, A. O retrato do colonizado precedido pelo retrato do colonizador. Rio de Janeiro: Paz \& Terra, 2004.

OLIVEIRA E.C.; PIRES, M.F.; VENTORIM, S. Paulo Freire: a práxis político-pedagógica do educador. Vitoria: Edufes, 2000.

ROMÃO, J.E.; GADOTTI, M. Paulo Freire e Amílcar Cabral: a descolonização das mentes. São Paulo: Instituto Paulo Freire, 2012.

UNESCO-UIS. Les adolescents non scolarisés. Montreal: Unesco-UIS, 2010.

Recebido em 8 de outubro de 2012.

Aprovado em 26 de setembro de 2013. 